\title{
DESENVOLVIMENTO DE UM METATEXTO DIDÁTICO PARA ALUNOS DO ENSINO MÉDIO
}

\section{Development of a Didactic Metatext for High School Students}

\author{
Francisca Natália Leite LOPES \\ Programa de Pós-Graduação em Linguística Aplicada \\ Universidade Estadual do Ceará \\ francisca.natalia@aluno.uece.br \\ https://orcid.org/0000-0002-5626-0077 \\ Francisco Ismael Araújo REBOUÇAS \\ Universidade Estadual do Ceará \\ ismaelreboucas@yahoo.com.br \\ https://orcid.org/0000-0002-5154-5700 \\ Luiz Eleildo Pereira ALVES \\ Universidade Estadual do Ceará \\ eleildo.alves@uece.br \\ https://orcid.org/0000-0003-4109-0455
}

\begin{abstract}
RESUMO: Este artigo tem como objetivo relatar uma experiência de desenvolvimento de metatexto didático à luz dos pressupostos sociocognitivistas da linguagem e discutir como as questões desse metatexto revelam uma interseção entre teoria e prática. Para tais reflexões, discutimos questões importantes no que tange ao conceito de texto como evento comunicativo (BEAUGRANDE, 1997), bem como ao de atividade didática como metatexto à luz de Costa, Monteiro e Alves (2016) e à ideia de leitura como um sistema complexo (FRANCO, 2011). Construímos uma atividade a partir do poema Ismália, de Alphonsus de Guimaraens, voltada a alunos do $1^{\circ}$ ano do ensino médio. Selecionamos seis questões, bem como o texto introdutório, para analisar os processos envolvidos no desenvolvimento desse metatexto. Intencionamos, com o desenvolvimento desse metatexto, estimular a leitura de um texto literário dentro da perspectiva de texto como evento comunicativo (BEAUGRANDE, 1997), em que todos os elementos, linguísticos e extralinguísticos, servirão de base à construção de sentidos, induzindo a autonomia do aluno em sala de aula. Desse modo, espera-se que o ensino de língua materna não proporcione somente o desenvolvimento de habilidades linguísticas e estruturais, mas que também revele questões cognitivas do discente em face à emergência de sentidos mais amplos.
\end{abstract}

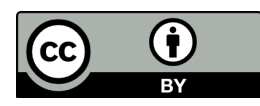


PALAVRAS-CHAVE: Metatexto didático; Ensino de língua materna; Aprendizagem situada; Leitura.

\begin{abstract}
This paper aims to report the experience related to the development of a didactic metatext under the light of the sociocognitive assumptions of language and to discuss how the tasks related to this metatext reveal an intersection between theory and practice. In order to conduct these reflections, we discuss significant aspects about the concept of text as a communicative event (BEAUGRANDE, 1997), as well as the didactic activity as a metatext under the theorical framework of Costa, Monteiro and Alves (2016) and the idea of reading as a complex system (FRANCO, 2011). We have built an activity based on the poem Ismália, by Alphonsus de Guimaraens, aimed to the first year of high school. We selected six aspects of this metatext, as well as the introductory text, to analyze the processes that were involved in this metatext production. With the development of this metatext, we intend to stimulate the reading of a literary text under the perspective of text as a communicative event (BEAUGRANDE, 1997), in which all the elements - linguistic and extralinguistic - function as the basis for the construction of meanings, inducing student's autonomy in the classroom. Thus, it is expected that the teaching of mother tongue not only propitiate the development of linguistic and structural skills, but also that they reveal student's cognitive aspects under the light of wider meanings emergence. KEYWORDS: Didactic metatext; Mother language teaching; Situated learning; Reading.
\end{abstract}

\title{
CONTEXTUALIZANDO NOSSA PROPOSTA
}

O Ensino Médio, conforme documento da Base Nacional Comum Curricular (BNCC) (BRASIL, 2017, p. 461), "é a etapa final da Educação Básica, direito público subjetivo de todo cidadão brasileiro"; ou seja, trata-se de um direito que, juridicamente, a todo cidadão é resguardado pelo Estado. O próprio dispositivo ainda ressalta que em face à realidade da educação brasileira, esta etapa da educação básica representa um desafio em meio ao desempenho insuficiente do alunado ainda no Ensino Fundamental. Além disso, podemos dizer que a organização do currículo atual do ensino médio é uma abordagem pedagógica executada na escola que se distancia bastante da realidade dos alunos. (BRASIL, 2017).

O documento da BNCC (BRASIL, 2017, p. 7) regulamenta as "aprendizagens essenciais que todos os alunos devem desenvolver ao longo das etapas e modalidades da Educação Básica”, de modo que se objetiva a asseguração de direitos de aprendizagem e 
de desenvolvimento dos alunos, conforme o Plano Nacional de Educação (PNE). Quando se refere à área de Linguagens e suas tecnologias, no tocante ao Ensino Médio, a BNCC (BRASIL, 2017, p. 470) indica o seguinte foco:

No Ensino Médio, o foco da área de Linguagens e suas Tecnologias está na ampliação da autonomia, do protagonismo e da autoria nas práticas de diferentes linguagens; na identificação e na crítica aos diferentes usos das linguagens, explicitando seu poder no estabelecimento de relações; na apreciação e na participação em diversas manifestações artísticas e culturais e no uso criativo das diversas mídias.

A proposta de um aluno autor e autônomo está relacionada à proposta de aprendizagem situada (COSTA, 2010), bem como a outras perspectivas de ensino/ aprendizagem que focam, justamente, as práticas de interação entre os alunos e os diversos elementos que perpassam nessas ações interativas. No tocante à relação entre teoria e prática, associação imprescindível e necessária a todo estudante de licenciatura, o metatexto apresentado neste artigo foi desenvolvido à luz da perspectiva de texto como evento comunicativo (BEAUGRANDE, 1997), considerando a abordagem complexa de leitura (FRANCO, 2011), que vê o texto como um evento dinâmico.

As reflexões apresentadas neste trabalho são decorrentes de uma prática concreta de elaboração e desenvolvimento de atividade de língua materna, que se deu ao longo da disciplina de Estágio Supervisionado IV em Língua Portuguesa, da Universidade Estadual do Ceará. Nesse sentido, este artigo tem como principal objetivo relatar uma experiência de desenvolvimento de metatexto didático à luz dos pressupostos sociocognitivistas da linguagem e discutir como as questões desse metatexto revelam uma interseção entre teoria e prática. Faz-se pertinente atentarmos para o uso da expressão desenvolvimento, que ganha singular importância na nossa abordagem, uma vez que consideramos incoerentes termos como aplicação ou elaboração para se referir à prática de construção de metatextos didáticos em contextos de aprendizagem, isso porque o professor não constrói a atividade sozinho, e o produto material não pode ser considerado, em si, como sendo toda a atividade, mas a interação que ela provoca, as desestabilizações que propõe e das quais emergem inúmeras situações de aprendizagem. Tudo isso corrobora o que veremos mais adiante: o metatexto é um produto e não um processo.

Para tais reflexões, discutiremos, a seguir, algumas questões importantes no que tange ao conceito de atividade didática como o metatexto à luz de Costa, Monteiro e Alves (2016), bem como tratar de leitura como um sistema complexo (FRANCO, 2011). 
Depois desse momento, passaremos à análise do metatexto didático que foi construído durante o processo de desenvolvimento teórico do referido estágio.

\section{FUNDAMENTAÇÃO TEÓRICA}

Sabemos que as metodologias de ensino de língua materna são direcionadas pelas perspectivas teórico epistemológicas dos estudos da linguagem. Quando se pensava, por exemplo, em uma ideia de língua como instrumento da comunicação, observávamos práticas de ensino voltadas ao estudo da gramática e à percepção de normas da língua descontextualizadas de situações concretas de uso.

Costa, Monteiro e Alves (2016, p. 43) consideram, ao citar Blühdorn e Andrade (2009, p. 21), que "os estudos empreendidos pela Linguística Textual, desde a década de 60 do século XX até os dias atuais, revelam deslocamentos de diversas ordens: '(i) da teoria para a aplicação; (ii) do texto abstrato para o texto concreto; (iii) do microtexto para o macrotexto; (iv) das forças centrípetas para as forças centrífugas." Cada um desses deslocamentos implica uma prática de ensino mais alinhada à forma como se compreendia o objeto de estudo, ou seja, o texto.

Atualmente, ainda segundo Costa, Monteiro e Alves (2016, p. 43), situamo-nos em um quinto deslocamento, que seria da estabilidade para a instabilidade, característica fortemente endossada pela perspectiva sociocognitivista.

Demétrio (2018), ao tentar definir - sem objetivo dogmático - o que significa Sociocognição, contrapõe-se a abordagens que a entendem como mera justaposição de processos cognitivos e elementos socioculturais. Para a autora, assumir essa perspectiva, na verdade, é uma tentativa de:

compreender a produção de sentidos como uma atividade criativa, uma vez que os falantes operam com a indeterminação de sentidos apriorísticos e, portanto, com a indicialidade da linguagem; modeladora, porquanto os sujeitos fabricam e reiteram, com suas práticas discursivas, versões compartilhadas do mundo; e correcursiva, visto que os indivíduos interagem recorrentemente, coordenando consensualmente condutas e coordenações de condutas, o que resulta numa dinâmica de recursão na consensualidade, num processo coordenado de referências à história de negociações e consensos anteriores (DEMÉTRIO, 2018, p. 25, grifos nossos).

Em Costa, Monteiro e Alves (2016, p. 44), entendemos que a visão epistemológica da Sociocognição “rejeita o 'isto ou aquilo’ das oposições do tipo 'externalismo versus 
internalismo', 'interação versus cognição' etc. nas relações entre linguagem, mente e mundo." Assim sendo, não é objetivo dos estudos desenvolvidos a partir da Sociocognição "pleitear qualquer postura dogmática ao postular a realidade como um efeito situada e socialmente validável” (DEMÉTRIO, 2018, p. 16). Dessa forma, a Sociocognição não se restringe a analisar elementos específicos que explicam os produtos da construção de sentido, como pensam as abordagens dualistas, mas se volta aos processos, considerando todos os elementos neles envolvidos, tentando construir um olhar integrativo sobre nossas práticas de/na linguagem.

Conforme entende Demétrio (2018, p. 24), a Sociocognição "tornou evidente a complexidade de fatores envolvidos nos processos de produção e compreensão textual e favoreceu o redimensionamento da própria noção de texto". Guardadas as devidas proporções, vemos em Beaugrande (1997) uma das propostas de definição de texto mais coerentes com essa noção de linguagem. Para esse autor, o texto é um "um evento comunicativo no qual convergem ações linguísticas, cognitivas, e sociais, e não apenas como a sequência de palavras que foram ditas ou escritas" (BEAUGRANDE, 1997, p. 11). Portanto, defender o fenômeno do texto como um evento comunicativo implica considerar a negociação de fatores multissistêmicos a cada processamento, considerando a complexidade das negociações e possibilidades na interação de cada participante, do ponto de vista colaborativo e solidário.

Em Costa, Monteiro e Alves (2016), ao refletirmos sobre essa definição, proposta por Beaugrande, observamos que, ao mencionar elementos linguísticos, o autor está aludindo à concretude do texto, compreendendo os elementos gráficos e demais elementos semióticos. Para Beaugrande (1997), a parte material que visualizamos do texto é apenas uma porção de matéria exposta, a ponta de um iceberg, em que, na parte submersa, estariam diversos outros processamentos complexos implicados no "fazer emergir" de sentidos sempre que um texto é lido.

Posicionando-se dentro do que ele chama de "paradigma ecológico", em oposição ao "paradigma consumista", Beaugrande entende o fenômeno do texto como um empreendimento humano. Em seu dizer, "um texto não existe, como texto, a menos que alguém o processe" (BEAUGRANDE, 1997, p. 15). Negando a compreensão reificadora do texto, Beaugrande define-o, ainda, como um sistema de múltiplos sistemas interconectados, como "sons, palavras, significados, os participantes do discurso, as ações em um plano, e assim por diante” (BEAUGRANDE, 1997, p. 11).

Pensar o ensino de língua materna à luz desse novo paradigma implica diferenciar, como propõe Costa (2010), estratégias de ensino voltadas para a instrução de conteúdo 
a propostas direcionadas à aprendizagem situada. Nesse sentido, a educação de língua materna se volta ao contexto das nossas ações diárias, buscando uma perspectiva interacionista de ensino-aprendizagem em que se almeja um posicionamento mais crítico e autônomo do aluno no tocante à emergência e à produção de sentidos. O texto, nesse aspecto, torna-se um elemento significativo e imprescindível nas interações durante o processo de reconstrução do conhecimento.

No contexto escolar, por profusas vezes, essa visão é um tanto estigmatizada, pelo fato de os alunos acharem, por consequência do ensino instrucionista, que o texto é somente aquilo que se encontra escrito em livros ou em outros suportes, como os digitais. Comumente, nessa perspectiva de instrução, há uma tendência equívoca de refutar a ideia do texto em semioses distintas àquelas do texto grafado, tais como figuras e outras representações que, de certa forma, não têm a palavra como elemento estruturante, mas sim elementos imagéticos os quais enquadram as ações sociocognitivas do leitor para além de termos linguísticos. É dessa forma que estes últimos revelam a inter-relação dos aspectos cognitivos e sociais ao encontro da interpretação do texto.

Corroborando essa ideia de texto como um construto de várias ordens, é importante que os alunos possam desenvolver suas habilidades de textualização e, sobretudo, de leitura, de modo que construam sentidos na interação de múltiplas semioses. Portanto, aliada à perspectiva sociocognitivista, compreender a atividade didática como metatexto é essencial no processo de ensino-aprendizagem. Para Costa, Monteiro e Alves (2016), o metatexto é uma relação complexa entre texto e contexto, que, por sua vez, consiste na emergência de fatores para além da materialidade textual.

Quando estamos em aula, por exemplo, desenvolvemos sempre textos em torno de outros textos. A fala do professor, a fala dos alunos, o próprio material didático, os registros na lousa e nos cadernos, tudo isso é metatexto, na visão de Costa, Monteiro e Alves (2016). Os referidos autores diferenciam, ainda, metatexto descontextualizado de metatexto contextualizado. $O$ primeiro tipo corresponde às práticas desenvolvidas dentro de uma perspectiva instrucionista de ensino. O segundo, por sua vez, situa-se na perspectiva integrativa, complexa e, por isso, sociocognitiva de aprendizagem, entendendo-se, dessa forma, que o aprender é construção e não instrução. O questionamento autorreconstrutivo (DEMO, 2002) e as questões condutivas, como pistas para a amplificação do texto (FERREIRA, 2019), são características importantíssimas desse segundo tipo de metatexto, que, neste trabalho, chamamos de metatexto didático situado. 
Marcuschi (2008, p. 61) afirma ser a língua uma prática sociointerativa, que é desenvolvida em "contextos comunicativos historicamente situados". Consoante a isso, é esperado que, por meio das atividades e das propostas de ensino em sala de aula, os alunos possam resgatar argumentos relevantes de suas práticas cotidianas, associandoos às questões de ordem linguística. Nesse sentido, o contexto ao qual estão inseridos favorece o desenvolvimento de atividades no tocante à emergência do sentido do texto por meio de questões que se relacionam aos aspectos estruturantes da língua.

No que tange aos processos de leitura, dentro dessa perspectiva sociointerativista, trazemos Franco (2011) e seus relevantes estudos sobre o que chama de abordagem "complexa de leitura". O autor perpassa três momentos importantes que descrevem as abordagens de leitura ao longo do tempo, que se baseavam, principalmente, nas concepções de língua de cada época.

A abordagem decodificadora baseava-se na linguagem como mero instrumento de comunicação, sustentando-se na ideia de leitor passivo, aquele que apenas extrai significado do texto, com ênfase no estudo da gramática e do vocabulário. A psicolinguística, por sua vez, teria a linguagem como espelho do raciocínio individual, numa visão que se opõe à da decodificação da leitura, que, de certa forma, é problemática, pois o leitor é bastante autônomo nas suas aferições, antecipando informações que, muitas vezes, podem não ser comprovadas pelo próprio texto. Por fim, a abordagem interacional, em que a perspectiva de significado não estaria presente nem no leitor, nem no texto propriamente dito, mas na interação entre esses dois elementos.

É interessante entender esses três momentos de leitura abordados por Franco (2011) pelo fato de ser evidente a observação de algumas posturas semelhantes tomadas por alunos durante atividades que envolvem a leitura e a interpretação de textos diversos. A motivação, para muitos deles, por força das experiências oriundas dos estágios curriculares, ocorria porque seriam avaliados futuramente por meio das atividades propostas. Dessa forma, é um desafio constante fazer com que os exercícios de leitura se efetuem como fruição, intenção que corrobora todo nosso planejamento didático das aulas, dentro dessa perspectiva de texto como evento e de leitura como atividade complexa.

A seguir, apresentaremos a atividade desenvolvida e teceremos discussões acerca da sua produção no decorrer da disciplina de Estágio Supervisionado IV. 


\section{DESENVOLVIMENTO DO METATEXTO DIDÁTICO}

Durante a fase teórica da disciplina de Estágio, fomos designados a elaborar uma atividade com temática livre, a qual fosse direcionada a alguma etapa do ensino médio. Essa atividade deveria ser construída sob a perspectiva do texto como evento comunicativo (BEAUGRANDE, 1997), para que, durante a fase de regência do estágio, fosse desenvolvida junto à turma. Posterior a isso, deveríamos tecer reflexões sobre nossas perspectivas acerca do processo de elaboração das questões do metatexto didático. É importante destacarmos que a inspiração para a proposta teórico-metodológica de desenvolvimento da atividade foi a Revista SiaráLendo, parte do projeto PreparAção: rumo ao ensino médio (2008), material desenvolvido por professores e estudantes das universidades públicas cearenses ${ }^{1}$.

Desse modo, construímos uma atividade a partir do poema Ismália, de Alphonsus de Guimaraens, com foco no $1^{\mathrm{o}}$ ano do ensino médio. Os conteúdos linguísticos pensados para a atividade eram estes: denotação e conotação; figuras de linguagem; elementos da literatura e da arte; debates reflexivos sobre as abordagens semânticas e conceituais do texto. Mais adiante, relacionamos esse conteúdo explorado nas questões às habilidades da BNCC.

A atividade possui dez questões, das quais selecionamos seis para análise neste trabalho. $\mathrm{O}$ foco central do metatexto didático que construímos era estimular a leitura de um poema dentro da perspectiva de texto como evento comunicativo (BEAUGRANDE, 1997), em que todos os elementos, linguísticos e extralinguísticos, servissem de base à construção de sentidos. Nossas análises serão à luz de teóricos que comungam essa ideia de texto.

Demo (2019) ressalta que uma experiência de sala de aula pode ser real, mesmo que seja uma simulação, ao abordar a questão da autenticidade no ambiente de ensino/ aprendizagem. Dessa forma, a aprendizagem é mais efetiva quando se utilizam elementos de cunho autêntico, ou seja, que proporcionem a aprendizagem situada, na medida em que depende pesadamente do contexto em que se está inserido e, portanto, encaixando-se na vida real do aluno. Assim, entendemos que, ao desenvolvermos metatextos didáticos situados, estamos desenvolvendo contextos de aprendizagem, e, além disso, projetando situações favoráveis à reconstrução do conhecimento por parte dos sujeitos que interagem conosco em sala de aula.

\footnotetext{
${ }^{1}$ Para mais informações, confira Monteiro (2014). 
Em vista disso, a atividade elaborada busca o desenvolvimento de uma perspectiva de aprendizagem autêntica. Os conteúdos não são lançados como desafios gramaticais, mas de uma forma que possam ser correlacionados com questões cognitivas e sociais do próprio aluno a quem se destinam as questões. Essa ideia de metatexto didático situado na construção de contextos de aprendizagens dialoga pacificamente com a proposta de Demo (2019), quando este destaca que aprendizagem autoral se revela na possibilidade de se desenvolverem raciocínios autônomos, realistas e instigantes.

Passemos, pois, à análise do metatexto por nós desenvolvido. Inicialmente, é proposto um diálogo introdutório, a partir do qual se pretende apresentar a atividade e fazer um chamamento para que o discente se sinta convidado a executar as propostas elencadas pela atividade, como vemos a seguir:

Figura 1: Apresentação da atividade de Língua Portuguesa.

\title{
ATIVIDADE DE LÍNGUA PORTUGUESA ${ }^{1}$
}

\begin{abstract}
Olá, amigo (a)!
Você tem o hábito de ler poesias? A seguir, propomos a leitura do poema Ismália, de Alphonsus de Guimaraens. Você já conhecia este autor? Lembra-se de outro poema que tenha lido e de que tenha gostado?

Observemos que, apesar de ser um texto bem pequeno, esta poesia carrega muitos elementos na linguagem que intensificam o tom de mistério e de emoções da narrativa, bem caracteristicos da linguagem poética.

O título do poema, Ismália, refere-se, exatamente, à personagem que vivencia essas emoções. Será que você, de alguma forma, se identificará com ela? Será que Ismália é uma personagem que irá lhe causar algum tipo de emoção? Afinal, é uma das características da poesia que, além de manifestar emoções, reflexões, ainda apresenta bastante expressividade.

Reflita sobre todas essas questões e, ao final, procure compartilhar com os seus colegas a sua percepção com relação ao texto antes e depois da realização da atividade.

Vamos lá!
\end{abstract}

Fonte: Elaborado pelos autores.

Por meio desse diálogo introdutório, convidamos os alunos à reflexão sobre algumas ideias que serão abordadas na atividade. É importante observar que essas Revista X, v. 16, n. 3, p. 861-883, 2021. 
questões são tentativas de construção de um metatexto didático oral ${ }^{2}$. Aqui cabendo uma reflexão a respeito: ainda há a crença de que os estudantes só aprendem se houver registro escrito. A cópia da "explicação" no quadro, ou mesmo a quase sempre desnecessária cópia no caderno de conteúdos que estão no livro, práticas que mais desgastam que constroem contextos de aprendizagem. É necessário repensarmos a necessidade de abrirmos espaço para o trabalho com o metatexto oral. A discussão com os alunos é rica fonte de aprendizagem, pois provoca inquietações, deslocamentos, conflitos e reelaboração de pensamento.

No entanto, destaca-se que essa abertura para a discussão precisa ser uma prática sincera, não meros "remendos" de espaços metodológicos, "cumprimento de tabela", em que se questiona um ou outro aluno e encerra-se o caso, passando-se ao tópico seguinte. Precisamos estar dispostos ao diálogo em sala de aula. Para isso, porém, o professor precisa ter a segurança que tal prática não será interpretada pela coordenação ou pelos pais como "enrolação". Por isso urge que toda a comunidade escolar repense o que se está entendendo por aprendizagem.

Atentos às críticas apontadas por Ferreira, Souza e Costa (2019), ao estudarem a perspectiva metodológica das sequências didáticas, procuramos ter o cuidado ao elaborarmos as questões da atividade, de modo que não parecessem segmentadas em blocos, como etapas, mas que tivessem continuidade. Estava latente a ideia de que os participantes deveriam se voltar ao texto, em uma perspectiva em que se valoriza "a língua em contextos de uso naturais e reais" (MARCUSCHI, 2016, p. 18), conforme podemos visualizar na primeira questão da atividade a seguir:

Figura 2: Primeira questão analisada.

1. Na primeira estrofe, o eu lírico deixa bem claro que Ismália enlouqueceu. É possível, a partir das pistas espalhadas pelo texto, identificar as possiveis causas desta situação? Caso sim, justifique-se, por meio de pelo menos um trecho extraído do texto. Caso não, procure estabelecer uma relação possível que possa ter contribuído ao estado de loucura da personagem.

Fonte: Elaborado pelos autores.

\footnotetext{
${ }^{2}$ Orienta-se a leitura da pesquisa de Marques (2019), que dá bastante abertura à discussão sobre o trabalho com o metatexto oral em sua pesquisa, em que a autora parte de debates sobre direitos humanos com estudantes do ensino médio, para discutir teoricamente as marcas discursivas que evidenciam a construção de pontos de vistas desses sujeitos interlocutores no processo de interação nas aulas de Língua Portuguesa.
} 
Nessa questão, propomos que se estabeleça a percepção sobre alguns elementos que não estão registrados na materialidade textual. A partir da leitura do poema, o aluno não poderá identificar a possível causa da loucura da personagem, conforme se vê nestes trechos (Quando Ismália enlouqueceu, pôs-se na torre a sonhar, [...] Queria subir ao céu, Queria descer ao mar e, no desvario seu, na torre pôs-se a cantar). Assim, espera-se do discente que possa, por meio de inferências e de seu pensamento reflexivo/ criativo, posicionar-se quanto à(s) possível(is) causa(s) da condição do estado mental da personagem, como, por exemplo, perceber uma decepção amorosa, ou outro similar, ou algo totalmente inesperado, que se soma a sua compreensão textual.

Portanto, procuramos estabelecer uma noção de produção textual aliada à ideia de atividade linguística autêntica, conforme Marcuschi (2000). Com efeito, pretende-se privilegiar a produção textual autoral em uma condição aliada às situações cotidianas orais ou escritas, de modo que se incorporem aspectos linguísticos, sociais e cognitivos, importantes para o desenvolvimento do discente e para o real funcionamento da língua.

Outro aspecto que julgamos interessante da atividade diz respeito à relação que é feita com a dimensão contextual à luz do que conceitua Hanks (2008), para quem o contexto é constituído por um duplo movimento de emergência e de incorporação. Tentamos explorar essas relações partindo do texto e relacionando ao contexto mais imediato dos discentes. Nesse jogo de (re)construção de sentidos, vejamos o que tentamos explorar na questão seguinte:

Figura 3: Segunda questão analisada.

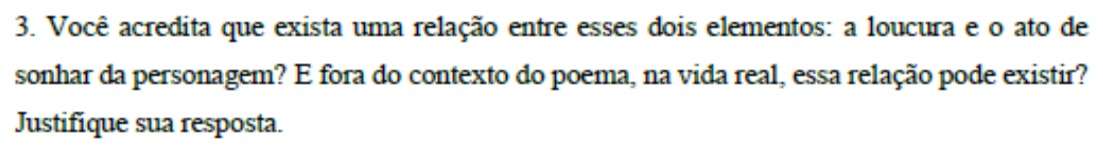

Fonte: Elaborado pelos autores.

Nessa questão, há a proposta de que o aluno possa estabelecer relações entre os dois elementos: loucura e sonho, os quais envolvem a personagem do poema e evidenciam o eixo temático abordado na questão analisada anteriormente. Pode ser que seja perceptível o fato de Ismália ter enlouquecido e por isso, tenha acabado se perdendo Revista X, v. 16, n. 3, p. 861-883, 2021. 
da realidade, passando a viver em um mundo imaginário. Entretanto, quais serão as reflexões geradas sobre isso fora do contexto imediato do poema? Isto é, quais são os outros enquadramentos possíveis durante as relações de sentido construídas por meio das interações entre o leitor e os diversos elementos que envolvem o texto, em outras palavras, que estão ao seu redor? São esses os aspectos que tentamos explorar nesta questão.

Outrossim, é interessante ressaltar que abordamos uma temática comumente associada ao currículo escolar do $2^{\circ}$ (segundo) ano do ensino médio, que é o movimento literário/artístico denominado Simbolismo, tentando fazer isso pela estética do texto e não dando prioridade aos elementos históricos do movimento. Assim, distanciamo-nos de algumas propostas pedagógicas que ensinam mais história da literatura que propriamente o texto literário ${ }^{3}$. Vejamos de que forma construímos a próxima questão da atividade:

Figura 4: Terceira questão analisada.

4. Você conhece o Simbolismo*? Que tal lermos um pouco sobre esse movimento literário do final do século XIX?

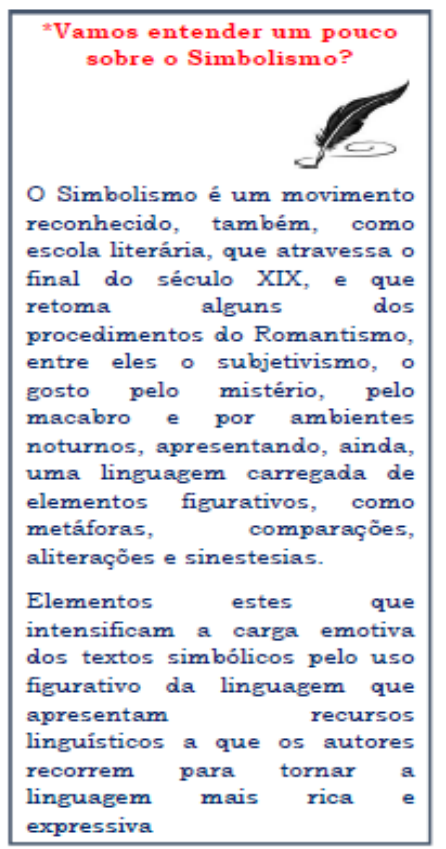

$\Rightarrow$ Caro aluno, sobre o que lemos do Simbolismo e, conforme a leitura realizada do poema Ismália, podemos perceber que:

a) O poema Ismália não apresenta figuras de linguagem em sua composição, não sendo, um desses elementos, responsáveis pela emoção e expressividade em que o poema se configura e se constrói.

b) Elementos como o mistério e o macabro são questões facilmente identificáveis nesse poema, A narrativa se passa durante o período da noite e em uma torre próxima ao mar, o que sugere um ambiente sombrio e atormentador em que a personagem se insere.

c) Uma outra característica do movimento simbolista é a representação de elementos religiosos em suas narrativas, o que não se observa, porém, neste poema.

Fonte: Elaborado pelos autores.

\footnotetext{
${ }^{3}$ Também procuramos desvencilhar a educação literária de uma tendência estruturalista de ensino que, conforme ressalta Ipiranga (2019), vai de encontro a uma tendência de priorizar leitura de obras literárias conforme a periodização tradicional das escolas literárias.
} 
Ressaltamos, primeiramente, que procuramos desenvolver domínios que, comumente, pela abordagem estruturalista de ensino, são destinados a serem "ensinados" somente em séries específicas. Desse modo, priorizamos uma perspectiva de ensino complexa em detrimento a uma abordagem de sequências previamente didatizadas, conforme explicado anteriormente. Nesse sentido, não nos prendemos somente à organização curricular que define quais objetos do conhecimento serão ministrados em determinadas séries, de forma que acaba restringindo, por vezes, o acesso a conhecimentos mais amplos e não-lineares ao que está ao redor do discente.

Logo, procuramos romper essa lógica da fragmentação de conteúdos percebida, conforme já mencionado, em livros didáticos, inicialmente, por meio de um metatexto com informações acerca da abordagem temática tratada, Simbolismo. Portanto, a referida questão busca auxiliar, trazendo algumas características sobre o movimento e sobre a produção literária daquela época. Assim, o fragmento deve ser a motivação para as discussões propostas.

Sobre o uso do metatexto didático, conforme dissertam Costa, Monteiro e Alves (2016), trata-se de um importante papel condutor na construção de sentidos. Na atividade, em questões distintas, utilizamo-nos, por diversas vezes, desse recurso de interação dos conteúdos, de modo que as informações são detalhadas dentro de uma caixa, ao lado do item proponente, em que se descrevem justamente alguns conceitos chaves e explicações relevantes para elucidar fatos importantes sobre o eixo temático específico. Dessa forma, poderá o discente ter uma noção geral sobre o assunto, de modo que isto o ajude no momento da resolução das questões. A ideia é que o metatexto seja um direcionamento tanto para ele, quanto para o professor, que deverá se posicionar e instigar a reflexão sobre os temas propostos a cada questão.

Nas questões cinco e oito, propusemos uma discussão do emprego e uso de figuras de linguagem, que, de certo modo, relaciona-se com aspectos ligados à linguagem denotativa e conotativa, com foco no estabelecimento do contexto literário que já vinha sendo discutido. Vejamos as questões: 
Figura 5: Quarta questão analisada.

5. Vamos reler a geguinte estrofe:
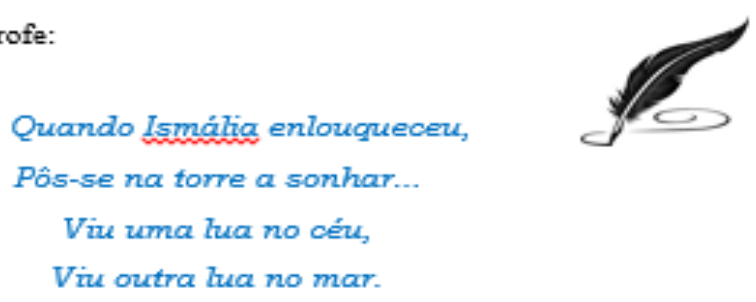

No terceiro e no quarto verso, há a incorporação de dois elementos naturais: a lua e o mar. Podemos concluir que o destaque desses dois corpos:

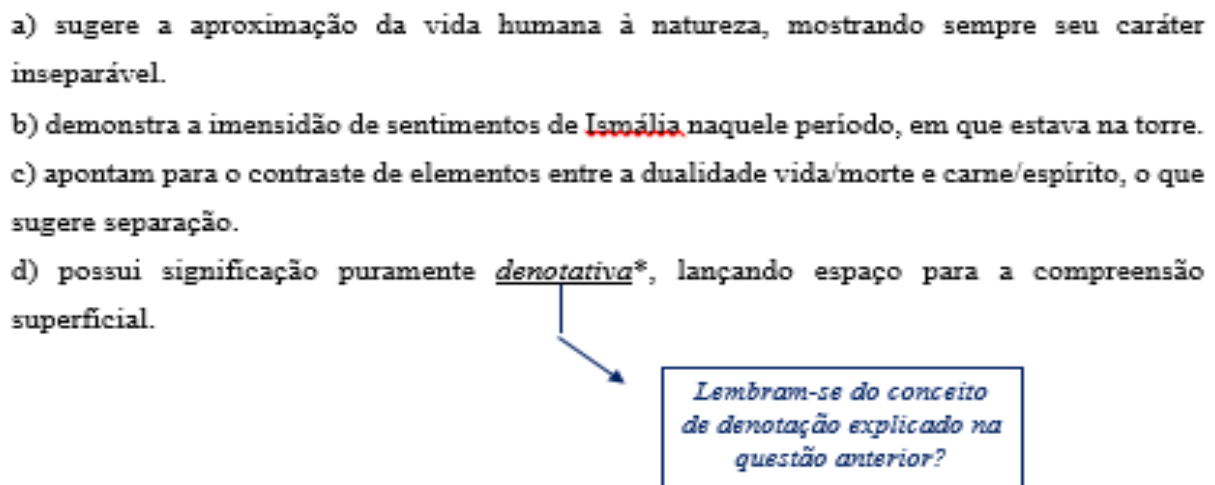

Fonte: Elaborada pelos autores.

Nessa questão, propomos, a princípio, uma releitura do texto para que haja uma possível atualização de sentidos, pois, à altura do desenvolvimento da atividade, esperase que a percepção sobre o poema, no sentido interpretativo, e também do ponto de vista conceitual-artístico, tenha sido acurada. Assumimos, dessa forma, o que Costa, Monteiro e Alves (2016) relatam sobre a ideia de que conceber o texto como evento: implica aceitá-lo por sua realidade dinâmica e pela instabilidade de sentidos que possui como um elemento constitutivo, dependendo, assim, de cada atualização motivada pelas interações que ora são estabelecidas entre o leitor e as interfaces inúmeras do texto.

$\mathrm{Na}$ questão em específico, procuramos estabelecer uma visão mais ampla sobre duas figuras tão salientes na mente de indivíduos, mas que, no poema, reconfiguramse como se fossem, praticamente, personagens secundárias da narrativa: a lua e o mar. Espera-se o entendimento de que há uma dupla visão com relação a esses elementos, bem como uma relação de contrastes do ponto de vista da personagem Ismália, em seus momentos de delírio. Sobre isso, é natural, conforme sugerimos, inclusive, em manuais 
do professor, a introdução sobre o tipo de linguagem atrelada aos textos literários, como o que se verifica neste. Aprofundamos um pouco mais sobre o referido assunto na questão oito, que possibilita o entendimento da importância desses recursos estilísticos para os efeitos de sentidos construídos pelas leituras.

Figura 6: Quinta questão analisada.

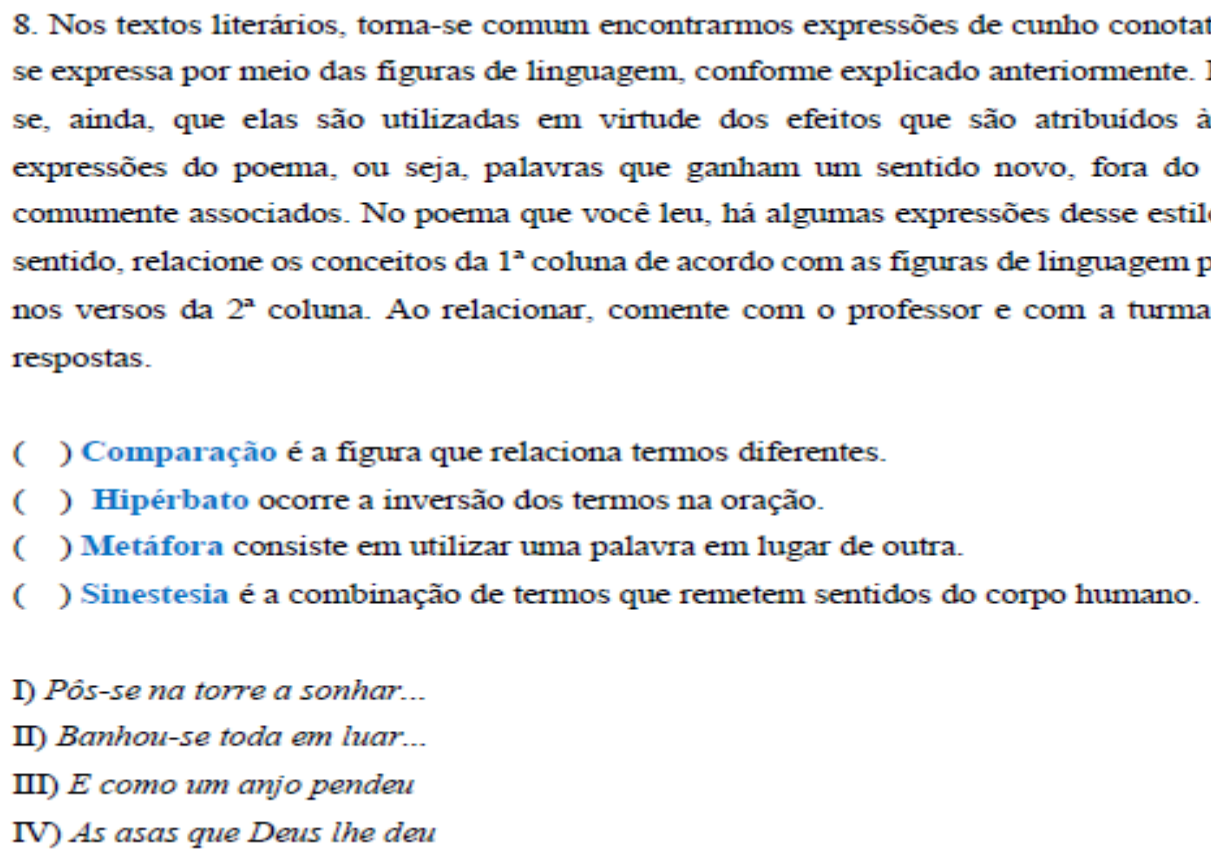

Fonte: Elaborado pelos autores.

A questão busca traçar um domínio acerca dos diversos recursos expressivos da língua e de como estes estabelecem jogos de linguagem dentro do contexto do poema. A atuação do docente é imprescindível no sentido de se fazer uma explanação acerca do delineamento das figuras de linguagem dentro do contexto dos versos, de modo que se chame atenção, prioritariamente, aos aspectos semânticos relacionados. Assim, ressaltamos, mais uma vez, a ideia de linguagem conotativa, já previamente explicada por meio de um outro metatexto complementar, logo ao início da atividade, conforme informação abaixo. 
Figura 7: Texto introdutório para a sexta questão.

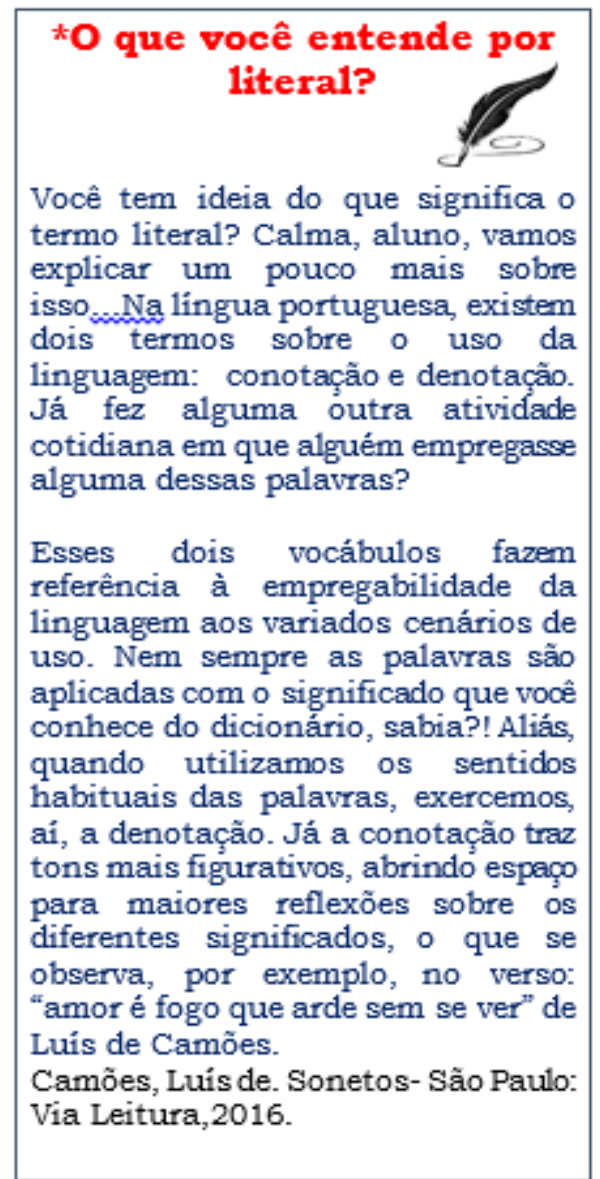

Fonte: Elaborado pelos autores.

Dando sequência às análises, elaboramos a nona questão no tocante à percepção do dialogismo presente nas estruturas textuais de diversas ordens e caracterizações. Nesse sentido, procuramos ressaltar um aspecto textual, que é a intertextualidade, cuja importância resvala nos processos de leitura e nos resultados significantes de construção de coerência e de sentidos. Importantes autores se dedicaram ao estudo desse construto textual, os quais trazemos para corroborar nossas perspectivas quanto à estruturação deste metatexto didático.

Koch (2000, p. 46) afirma ser o texto um objeto heterogêneo, o qual resulta de uma relação profunda entre os seus elementos externos e internos. Dessa exterioridade, a autora lembra que "fazem parte outros textos que lhe dão origem, que o predeterminam, com os quais dialogam, que retoma, a que alude, ou a que se opõe”. Marcuschi (2008, 
p. 132) vai ao encontro dessa perspectiva, de modo que podemos acrescentar o fato de que o autor ressalta a questão de ser um consenso, hoje, a ideia de que um texto sempre comunga de outro, nunca estando isolado, ou seja, afirmando, de certo modo, que não há ineditismo. Mais "do que um simples critério de textualidade, é também um princípio constitutivo que trata o texto como uma comunhão de discursos e não como algo isolado"( MARCUSCHI, 2008). Dessa forma, colaborando, ainda, para a construção da coerência e da interconexão com muitos outros elementos do mundo.

Por sua vez, no que tange à proposta dos campos de experiência da $\mathrm{BNCC}$, que, de certa forma, visam ao maior protagonismo dos alunos no ambiente de ensino/ aprendizagem, ao tocante das práticas de leitura, escuta, produção textual e análise linguística/semiótica, observa-se, também, essa questão sendo abordada, como algo emergente em duas habilidades descritas dentro dos campos de atuação social.

A primeira habilidade $(\mathrm{EM} 13 \mathrm{LP} 03)^{4}$ ressalta a importância de se analisar as relações intertextuais e interdiscursivas, como meio de se chegar à compreensão das relações dialógicas existentes entre os textos, bem como à compreensão de paródias e outras estilizações da língua. A segunda (EM13LP04), por sua vez, estabelece o nível de relevância da intertextualidade e da interdiscursividade no tocante à sustentação e à qualificação dos posicionamentos do indivíduo, no que se refere à ideia de se fazer uso de citações e de paráfrases de forma devida, quando necessário.

Como se vê, tais habilidades corroboram um aprendizado mais autêntico, tendo em vista possibilitar que o aluno exerça sua autoria no seu processo de ensinoaprendizagem. É importante lembrarmos que o metatexto aqui apresentado colabora, exatamente, para a possibilidade de múltiplas relações intertextuais, na medida em que elaboramos questões que mobilizam fatores interdiscursivos não só do texto grafado, mas também do texto imagético. Observemos a seguinte proposta de interação:

\footnotetext{
${ }^{4}$ Código alfanumérico utilizado pela BNCC, que significa o seguinte: EM (Ensino Médio); 13 (número que significa que as habilidades descritas podem ser desenvolvidas em qualquer série do Ensino Médio, conforme definição dos currículos; LP (Língua Portuguesa) e 03 (Sequência da habilidade). Com relação a este último, o documento da $\mathrm{BNCC}$ ressalta que não há uma hierarquia ou sequência rígida das habilidades, cabendo aos sistemas e às escolas "definir a progressão das aprendizagens, em função de seus contextos locais”. (BRASIL, 2017, p. 34).
} 
Figura 8: Sexta questão analisada.

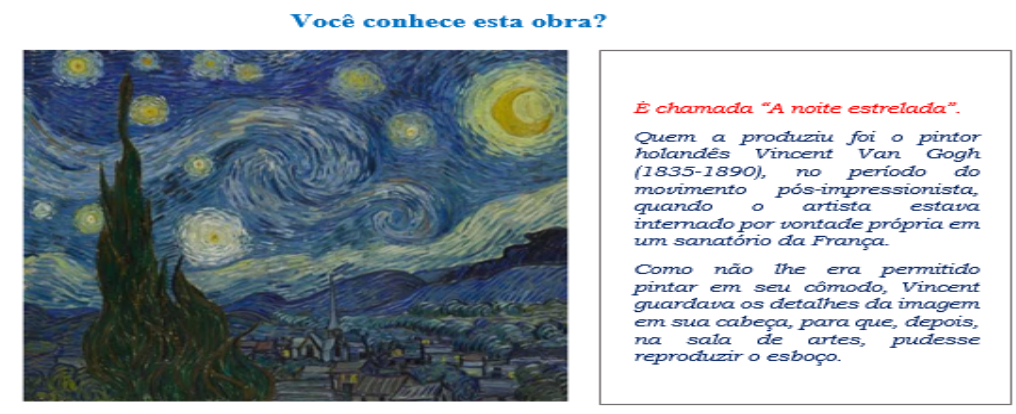

09. Ainda sobre nossos estudos com o poema Ismália, mas agora, também, diante da pintura $A$ noite estrelada, marque com um $\mathrm{X} o(\mathrm{~s})$ item(ns) mais condizente(s) com as análises das obras.

( ) A lua e as estrelas, nas duas obras, que pairam pelos céus notumos, podem atuar como corpos a que Ismália e o pintor buscassem respostas ou consolos diante de suas digressões/angístias.

() $\mathrm{O}$ uso do azul e o contraste de cores da pintura de Vincent Van Gogh traz à obra uma verificação de realidade e, também, mostra a face solitária do artista internado, meio à noite sombria, fato que se verifica, também, em Ismália.

( ) As duas obras, apesar da temática e das contextualizações parecidas, não dialogam entre si, já que contrastam diferentes noções sobre a resolução dos problemas de vida.

Saiba um pouco mais...
Em seu quadro A Noite Estrelada,
Van Gogh atinge o ápice de sua
capacidade artística, sendo o quadro
composto por técnicas de alto nivel que,
posteriormente, foram estudados e
considerados posteriormente como parte
do estilo denominado pós-impressionista.
(...) pode ser considerado um grande ápice
de seu próprio embate interno entre a
sanidade e delíio, entre a sua fé e o seu
dom artistico.
O próprio tamanho das estrelas é
desproporcional ao restante do quadro,
chamando a atençáo do admirador ao tom
vibrante e aceso das mesmas, que
parecem saltar e se destacar de todos os
demais tons mais escuros do quadro (...) o
vilarejo retratado no quadro, na verdade
náo existia. É sabido que o quadro foi
pintado a partir da janela de seu quarto no
hospicio, onde fora internado, mas deste
ponto de vista náo havia qualquer vilarejo.
A inserção no quadro indica um desejo do
pintor em retratar algo que estava além de
seu alcance.

Fonte: Elaborado pelos autores.

A princípio, apresentamos a pintura $A$ noite estrelada, do artista holandês Vincent Van Gogh, e, também, um metatexto complementar para a contextualização, caso o aluno não a conhecesse, ou simplesmente não soubesse questões conceituais dessa obra de arte. É esperado que, por meio de conhecimentos já salientados no decorrer da atividade no tocante às possibilidades de construção de sentido, o aluno possa perceber como os inúmeros recursos estilísticos empreendidos pela linguagem possibilitam a percepção de elementos intertextuais que aproximam as duas obras estudadas. 
Julgamos, nesse sentido, existirem relações dialógicas entre as duas manifestações textuais, de modo que intencionamos uma série de reflexões por meio dos itens proponentes. É esperado que se entenda os dois primeiros itens como corretos, por haver, primeiramente, uma correlação entre os elementos lua e estrelas como fatores de apoio, em meio à escuridão emocional em que poderiam viver o pintor e a personagem Ismália. Por sua vez, o segundo item propõe uma relação entre os sentimentos de ambos, Ismália e Van Gogh, quanto às tonalidades utilizadas pelo pintor, em se tratando do movimento impressionista e como isso pode vir a refletir na possível solidão vivenciada pelo pintor em tal momento, dadas as circunstâncias apresentadas pelo metatexto complementar.

É relevante citar o processo de produção da atividade como um constante aprimoramento de habilidades teóricas e práticas, visto que buscamos, acima de tudo, desenvolver um senso crítico/reflexivo por meio das questões propostas. Dessa forma, quando falamos em habilidades empreendidas, focamos em questões estruturais de nossa formação que, de forma massivamente positiva, é aliada à ideia do texto como um construto de interações, estando além de uma propriedade puramente linguística, ou seja, além da sua interface frástica.

Costa, Monteiro e Alves (2016) ressaltam muito bem essa questão da perspectiva do texto como um evento, apontando questões importantes no que tange a essa realidade dinâmica que quase sempre é negligenciada pelas metodologias de ensino de língua materna. De fato, requer maior disciplina e demanda de tempo pelo professor que, possivelmente, possa ter tido uma formação voltada a uma outra base teórica disciplinar.

Terminada esta seção, que se dedicou à análise de desenvolvimento de uma atividade de língua portuguesa, partimos para as nossas considerações finais, com foco na relevância da prática docente para a nossa formação como futuros professores de língua portuguesa.

\section{CONSIDERAÇÕES FINAIS}

Nosso trabalho teve como objetivo relatar uma experiência de desenvolvimento de metatexto didático à luz dos pressupostos sociocognitivistas da linguagem e discutir como as questões desse metatexto revelam uma interseção entre teoria e prática. $\mathrm{O}$ metatexto desenvolvido estabelece também um diálogo com a BNCC, mostrando que quando exploramos o texto como evento comunicativo, consequentemente, atendemos as habilidades necessárias à construção de aprendizagem dos discentes.

As questões construídas possibilitam uma aprendizagem situada, uma vez que todos os enunciados elaborados favorecem uma interpretação autônoma, assim 
como defende Demo (2019). Em outras palavras, à medida que se lê, a autoria do aluno prevalece, desde que seja dado espaço para essa construção de autonomia, não cerceando o discente com práticas monológicas de ensino, como copiar e corrigir, mas percebendo que a discussão é parte importante do processo de compreensão por meio das desestabilizações que os conflitos desencadeados proporcionam.

A respeito disso, encetamos a necessidade de darmos espaço à sincera construção do metatexto oral, mas também sinalizamos compreender que para o professor conseguir desenvolver isso com seus alunos, é necessário que todos repensem o que é aprendizagem, pois enquanto coordenadores estiverem se incomodando com "mapeamentos' de alunos restritos a lugares específicos na sala e chamando a atenção de professores por conta do "barulho" que as discussões provoca, não haverá espaço para contextos de interação. Enquanto pais estiverem cobrando professores por cadernos preenchidos e livros didáticos "vistos" de capa a capa, não haverá condições de o professor se constituir como um profissional autônomo diante do seu fazer.

É importante salientar que o metatexto apresentado neste trabalho, desde a seleção do texto que seria explorado até a definição dos conteúdos e o planejamento da aula de desenvolvimento, tudo isso foi feito por professores-aprendizes em um espaço de formação de estágio, é verdade, mas um espaço em que se tinha liberdade para a construção autoral, porque entendemos que o professor também precisa ser autor.

Dessa forma, o desenvolvimento da atividade estava focado na autonomia do aluno, mas também nos permitiu reconstruir conhecimento, no processo de elaboração e reelaboração, no deslocamento para pensar no outro. É por isso que defendemos um ensino de língua materna que não implique somente o desenvolvimento de habilidades linguísticas e estruturais, mas que, também, considerem questões cognitivas do discente em face à emergência de sentidos mais amplos, corroborando a ideia de texto como evento comunicativo (BEAUGRANDE, 1997) e de aprendizagem a partir da cognição situada (COSTA, 2010).

Atualmente, muito se fala de formação continuada de professores. Acreditamos que a formação mais eficaz é aquela que dá espaço para o professor pensar, ser autor, colocar em prática aquilo que ele lê, que ele escuta, que ele vivencia. É urgente pensarmos o lugar do professor como sujeito pesquisador competente e capaz de atuar sem "fiscalizações". Se metaforizarmos a relação teoria-prática ao ato de semear a boa semente, entenderemos que cada uma dá seu fruto a seu tempo, com suas singularidades, com suas necessidades, mas necessitando, sempre, de espaço para espalhar suas raízes. O 
grande equívoco da educação reside em anular as singularidades e esperar a mesma coisa de todos e, ainda, achar que isso é aprender.

\section{REFERÊNCIAS}

BEAUGRANDE, R. de. New foundations for a science of text and discourse. cognition, communication, and the freedom of access to knowledge and society. Tradução: COSTA, M. H. Norwood: Ablex, 1997. Disponível em: http://www.beaugrande.com/new_ foundations_for_a_science.htm. Acesso em: 25 ago. 2019.

BLÜHDORN, H.; ANDRADE, M. L. C. V. O. Tendências recentes da linguística textual na Alemanha e no Brasil. Tradução Hans. In: WIESER, H. P.; KOCH, I. G. V. (org.). Linguística textual: perspectivas alemãs. São Paulo: Lucerna, 2009.

BRASIL. Ministério da Educação. Base Nacional Comum Curricular. Brasília, 2017. Disponível em: http://basenacionalcomum.mec.gov.br. Acesso em: 20 ago. 2019.

CEARÁ. Secretaria de Educação. Siaralendo. In: PreparAção: rumo ao Ensino Médio Caderno de Lingua Portuguesa, Fortaleza, v. 1, 2008, p. 69-73.

COSTA, M. H. A. Linguagem como interlocução e aprendizagem como cognição situada, Linguagem em Foco. Fortaleza, v. 2, n. 2, p. 151-167, 2010. Disponível em: https://revistas. uece.br/index.php/linguagememfoco/article/view/1727. Acesso em: 20 ago. 2019.

COSTA, M. H.A.; MONTEIRO, B. C. B.; ALVES, L. E. P. Ensino de leitura na perspectiva do texto como evento: o desafio de fazer emergir o sentido. Diadorim, Rio de Janeiro, v. 2, n. 18, p. 42-66, 2016. Disponível em: https://revistas.ufrj.br/index.php/diadorim/ article/view/5360. Acesso em: 20 out. 2016.

DEMETRIO, A. K. B. Aspectos epistemológicos da sociocognição no discurso reflexivo de Clarice Lispector sobre o dizer: o malogro da voz e o esplendor de ter uma linguagem. 2018. 255 f. Tese (Doutorado) - Doutorado em Linguística Aplicada, Programa de PósGraduação em Linguística Aplicada, Universidade Estadual do Ceará, Fortaleza, 2018. Disponível em: http://www.uece.br/posla/wp-content/uploads/sites/53/2019/11/TESEALANA-KERCIA-BARROS-DEME\%CC\%81TRIO.pdf. Acesso em: 08 abr. 2020.

DEMO, P. Complexidade e aprendizagem: a dinâmica não linear do conhecimento. São Paulo: Atlas, 2002.

DEMO, P. Autenticidade. 2019. Disponível em <https://drive.google.com/file/d/1aQ_ n8we6INcmYPFXXDngGnh_LkYTgum3/view>. Acesso em: 27 mar. 2020. 
FERREIRA, K. da S. Leitura de poemas em sala de aula: a construção do evento textual a partir de pistas sugeridas pelo metatexto didático. 2019. 106 f. Dissertação (Mestrado) - Mestrado em Linguística Aplicada, Programa de Pós-Graduação em Linguística Aplicada, Universidade Estadual do Ceará, Fortaleza, 2019. Disponível em: http://www. uece.br/posla/wp-content/uploads/sites/53/2020/01/DISSERTA $\%$ C3\%87\%C3\%83O_ KANDICE-DA-SILVA-FERREIRA-1.pdf. Acesso em: 08 abr. 2020.

FERREIRA, K. da S.; SOUZA, A. K.; COSTA, M. H. A. (Não) Artificialização dos Gêneros Textuais nas Práticas de Ensino de Língua Materna. Linguagem em Foco, Fortaleza, v. 11, n. 1, p. 83-96, 2019. Disponível em: https://revistas.uece.br/index.php/ linguagememfoco/article/view/2939. Acesso em: 08 abr. 2020.

FRANCO, C. de P. Por uma abordagem complexa de leitura. In: TAVARES, K.; BECHER, S.; FRANCO, C. (Orgs.). Ensino de Leitura: fundamentos, práticas e reflexões para professores da era digital. Rio de Janeiro: Faculdade de Letras da UFRJ, 2011. p.2648. Disponível em: <http://www.claudiofranco.com.br/textos/franco_ebook_leitura.pdf> Acesso em: 27 jan. 2019.

HANKS, W. Língua como prática social: das relações entre língua, cultura e sociedade a partir de Boudieu e Bakhtin. São Paulo: Cortez, 2008.

IPIRANGA, S. D. da S. O papel da literatura na BNCC: ensino, leitor, leitura e escola. Revista de Letras, Fortaleza, v. 1, n. 106, p.106-114, jan./jun, 2019. Disponível em: http:// www.repositorio.ufc.br/bitstream/riufc/49493/1/2019_art_sdsipiranga.pdf. Acesso em: 10 abr. 2020.

KOCH, I. V. O texto e a construção de sentidos. 4. ed. São Paulo: Contexto, 2000.

MARCUSCHI, L. A. A Coerência no hipertexto. Recife: Universidade Federal de Pernambuco, 2000, mimeo. Disponível em: https://drive.google.com/file/d/1wqaBusCo HZzSpcbIW5DJVYjGaBHkcs2S/view. Acesso em: 01 abr. 2020.

MARCUSCHI, L. A. Produção Textual, Análise de Gêneros e Compreensão. São Paulo: Parábola, 2008.

MARCUSCHI, L. A. O papel da linguística no ensino de línguas. Diadorim, Rio de Janeiro, v. 18, n. 2, p. 12-31, jul/dez, 2016. Disponível em: https://revistas.ufrj.br/index. php/diadorim/article/view/5358/3929. Acesso em: 13 abr. 2020. 
MARQUES, D. T. Referenciação e ensino: uma análise sociocognitivista da (re) construção do ponto de vista. 2019. 122 f. Dissertação (Mestrado) - Mestrado em Linguística Aplicada, Programa de Pós-Graduação em Linguística Aplicada, Universidade Estadual do Ceará, Fortaleza, 2019. Disponível em: http://www.uece.br/posla/wp-content/uploads/ sites/53/2020/02/DISSERTA\%C3\%87\%C3\%83O_DENISE-TEIXEIRA-MARQUES. pdf. Acesso em: 12 mar. 2021.

MONTEIRO, B. C. B. A perspectiva sociocognitiva da referência na abordagem didática do texto: implicações na percepção do leitor aprendiz. 2014. Dissertação (Mestrado em Linguística), Programa de Pós-Graduação em Linguística Aplicada, Universidade Estadual do Ceará, Fortaleza, 2014. Disponível em: https://siduece.uece.br/siduece/ trabalhoAcademicoPublico.jsf?id=84042. Acesso em: 08 abr. 2020.

Recebido em: 14 jul. 2020. Aceito em: 14 mar. 2021. 